University of Nebraska - Lincoln

DigitalCommons@University of Nebraska - Lincoln

Faculty Publications: Department of Teaching, Department of Teaching, Learning and Teacher Learning and Teacher Education

Education

2006

Teacher Experiences of Culture in the Curriculum

Elaine Chan

University of Toronto, echan2@unl.edu

Follow this and additional works at: https://digitalcommons.unl.edu/teachlearnfacpub

Part of the Curriculum and Instruction Commons, and the Teacher Education and Professional Development Commons

Chan, Elaine, "Teacher Experiences of Culture in the Curriculum" (2006). Faculty Publications: Department of Teaching, Learning and Teacher Education. 376.

https://digitalcommons.unl.edu/teachlearnfacpub/376

This Article is brought to you for free and open access by the Department of Teaching, Learning and Teacher Education at DigitalCommons@University of Nebraska - Lincoln. It has been accepted for inclusion in Faculty Publications: Department of Teaching, Learning and Teacher Education by an authorized administrator of DigitalCommons@University of Nebraska - Lincoln. 


\title{
Teacher Experiences of Culture in the Curriculum
}

\author{
Elaine Chan
}

\begin{abstract}
This study examines the experiences of two middle-school teachers as they attempt to acknowledge the ethnic, linguistic, and religious diversity of their students in their curriculum and teaching practices. It identifies the complications and challenges they encountered in the process. It presents one curriculum event to explore the ways in which diverse beliefs and values intersected as the teachers implemented the event. It employs a narrative inquiry approach with an emphasis on stories to learn about the experiences of the participants.
\end{abstract}

Keywords: curriculum, ethnic identity, multicultural education, narrative enquiry, teacher knowledge

\section{Preamble}

Cultural and linguistic diversity are among the characteristic features describing the Canadian landscape. Eighteen per cent of the total population was born outside the country, and $11 \%$ of the population identify themselves as members of a visible minority group (Statistics Canada 1998, 2003). Not surprisingly, multiculturalism has been seen as a key educational issue. Yet, despite the importance of multiculturalism, there are all too few examinations of the interaction of culture and curriculum in school contexts.

There is a wealth of normative prescription about the acknowledgment of culture. Cummins (1996), Igoa (1995), and Wong-Fillmore (1991a, b) have highlighted the academic, emotional, and societal importance of acknowledging diversity by engaging students in learning about their home cultures and languages. Banks (1995) has highlighted the importance of the inclusion of culture in the curriculum as a means of developing positive attitudes among racial and/or ethnic minorities. Rodriguez (1982), Kouritzin (1999), and McCaleb (1994) have explored the dangers of the failure to acknowledge the cultural knowledge of students of ethnic minority backgrounds. Ada (1988) has discussed a project in which the families of students of 
minority background were engaged in bilingual literacy projects. Paley's (1995) "integrated" curriculum had parents and children discussing values, rituals, and cultural experiences through family stories in order to foster a sense of community within the classroom.

However, although there is much discussion outlining the importance of "information and awareness of the cultural backgrounds of pupils in order to better to diagnose strengths, weaknesses, and differences in cognitive styles" (Moodley 1995: 817), there is a lack of consensus about how best to acknowledge this diversity in a school context. In this paper, I examine the challenges and complications that two middle-school-level teachers encountered as they attempted to implement a curriculum event.

\section{Introduction}

The students came into Room 42 after lunch today with all kinds of questions about their upcoming field trip to Boyne River. They wanted to know when they would be leaving, when they would be returning, what they should bring, whether it would be cold at Boyne River, what they would eat, where they would sleep, and so on. They seemed very excited about the trip.

William answered their questions ... [but] when he asked for a show of hands of students from those who would be participating, I was surprised to see that many students did not put their hands up. Sahra, who was sitting directly in front of William, did not put her hand up.

"My father won't let me go," Sahra said. She explained that she could not go on field trips where they would be spending the night. Sahra's family is South Asian and her parents, especially her father, are very strict about the kinds of school activities they allow her to take part in.

"Do you want me to talk to him?" William asked her. "You should be able to go."

I asked some of the students sitting near me whether they would be going on the field trip.

"It's against my religion for girls to go out," Zeynab said.

"I can't. I need to go with my father to the hospital, to help translate for him."

"I need to pick my sister up from school and get my brother from daycare-my parents have to work."

"I work at my family's tea store, and sometimes I need to help them [i.e., my parents] with the forms." (Field note: November 2000)

I present this field-note documenting student responses to a school field-trip in order to introduce the complexities that two middle-school teachers at Bay Street School, William and Dave, faced as they attempted to acknowledge their students' ethnic, linguistic, and religious diversity in their curriculum and their teaching practices. The field trip to Boyne River, an outdoor- 
adventure center, provides a context for examining the intersection of diverse beliefs and values at Bay Street School. ${ }^{1}$ This intersection is at the core of the work done by teachers in Canada, and in particular in Toronto, as representatives, and members, of a receiving culture that has a reputation for welcoming immigrants. However, they work with students and families whose values and beliefs about education, and ways of interacting with others, may differ significantly from their own.

In Fall 2000, William and his colleague Dave were preparing to take their combined classes of 71 grade-8 students on a 4-day field trip to Boyle River. I center this discussion on the planning of this trip, one of many activities and events that occurred during the 3.5 years I spent as a participant observer at Bay Street School. ${ }^{2}$

Despite William's willingness to address issues of diversity in conversations with his colleagues and students, and to be culturally sensitive in his practices and in his curriculum, there were differences in perspective around the Boyne River trip, and other school activities. Thus, William and Dave found that there were a few parents who did not seem to support activities they undertook; there were tensions between members of ethnic groups in some interactions; and students sometimes did not seem especially interested in sharing aspects of their own cultures, or learning about the cultures of their peers. Given that the teachers at Bay Street School seemed to recognize the value of acknowledging culture by accommodating for differences in the curriculum, these tensions were always surprising.

I use Schwab's (1973) commonplaces of teacher, learner, subject matter, and milieu to explore how differences in perspective around a single curriculum event-the subject matterwere shaped by experiences that teachers, learners, their families, and other members of the school community brought with them to the school milieu.

Research on teachers' professional knowledge landscapes (Clandinin and Connelly 1996, Connelly and Clandinin 1999), the role of schooling in shaping a sense of ethnic identity (Wong Fillmore 1991a, b, Cummins 1996, Kouritzin 1999), experience and education (Dewey 1938, Connolly and Clandinin 1988), and narrative inquiry (Clandinin and Connelly 1994, 2000, Phillion 2002) form the theoretical framework for this study. Given Dewey's (1938) philosophy of the interconnectedness between education and experience, I see all that the students' encounter in their school context, as well as all that occurs in their school, home, and neighborhood, as experience with the potential to contribute to their learning about what a sense of ethnic identity may mean to them. This broad base of potentially influential interactions highlights the power of schooling experiences and further reinforces the importance of recognizing and celebrating the diversity that students bring to a school context.

\section{The Boyne River field trip}

Bay Street School had been placed on a list at the outdoor-education center to be contacted if another school canceled their booking. When a call came from Boyne River, the staff at Bay Street School began work to make arrangements in order for their students to participate. They developed an information package complete with translations of notices and waiver forms in 
different languages, made bookings for buses and supply teachers, and arranged for the teachers remaining in the school to cover the classes of those who would be accompanying the students to Boyne River. These arrangements were made within 3 days of receiving the call; for the teachers at Bay Street School, the field trip was a valuable activity.

Other members of the school community also supported the Boyne River trip. The community-development worker viewed the field trip as an opportunity for students who might not otherwise be able to participate in this kind of outdoor education activity to do so. He spoke about the importance of equality of access for children whose families might not be able to support learning opportunities of this kind outside of a school context.

Dave was the only one of the three grade- 8 teachers who was to accompany the students to Boyne River. He spoke of the field trip as an opportunity to interact with the students in a way different from their regular in-school and in-class interactions. His own experience as a camp counselor and outdoor-education teacher reinforced his personal philosophy in the value of interaction with individual students while participating in outdoor activities.

Marla, the special education teacher who worked with William and Dave, viewed the field trip as an opportunity for the students to gain experiences that were outside of the academic curriculum. She did not understand the unwillingness of some of the parents to send their children: she thought that the field trip was an especially important way for students who were not academically inclined to excel in a different area. She pointed to one student in particular who had difficulty sitting still, and who struggled academically, and stated that he would likely enjoy something like an outdoor-adventure trip.

\section{Bay Street School context}

William responded to Sahra's statement that she would not be able to participate in a class field trip by offering to speak to her father-to convince him of the value of the field trip and to emphasize to him the importance of female students having educational opportunities equal to those available to male students.

Such criticism by teachers of the unwillingness of some of the parents to permit their children to participate in the Boyne River field trip may suggest a lack of sensitivity to the backgrounds that the students were bringing to the school context. However, throughout my years of work in Bay Street School I saw examples of the teachers' willingness to learn about the cultures of their students, and to accommodate for different practices. William included discussions on cultural diversity and racism in social studies classes, addressing the injustice and prejudice that Native Canadians suffered in New France as his students learned about settlement in Canada. He read passages featuring the experiences of members of the Black community in Canada during Black History Month, and continued to incorporate information about the Black community. He had his students interview their parents in order to write about their childhood in their home countries before immigrating to Canada; he gave his students a family-studies project that involved the preparation of recipes translated from their parents' home language into English. During his first year at Bay Street School, he fasted during Ramadan 
along with his South Asian students. He supported the integrated international languages classes that are a part of the curriculum at Bay Street School, and demonstrated his desire to learn about the cultures and languages of his students by asking them about specific practices or about vocabulary or expressions in Chinese, Vietnamese, and Spanish.

William and Dave's recognition of the backgrounds of their students was also set in the context of a school community with a history of diversity that began with its establishment over 125 years ago (Connelly et al. 2003); the present student population at Bay Street School is highly diverse (Chan and Ross 2002). The school is in a neighborhood where immigrants settle $^{3}$ - in a city identified by the UN as the most culturally diverse in the world.

In other words, the members of the school community at Bay Street School seemed to be doing what is seen as important in creating a culturally sensitive curriculum and school context. Nonetheless, the implementation of curriculum events was met with resistance by some students and parents. The difficulties that the teachers encountered as they attempted to be sensitive to the needs of their diverse student population can be explored in terms of Clandinin and Connelly's (1996: 25) distinction between cover stories, sacred stories, and secret stories about multicultural education and a culturally sensitive curriculum. Thus, the secret stories of what is actually lived on the school landscape and in classrooms are often not presented or explored because they counter a public need to believe that schools are meeting the needs of a culturally diverse student population. However, these secret stories recognize that the process of acknowledging culture in the curriculum is complicated: good intentions may be misconstrued, or individuals may bring to the school context experiences that shape their interpretations of school events in ways that differ significantly from what was intended.

\section{Differing student perspectives}

Although the teachers and administrators at Bay Street believed in the value of the field trip to Boyne River, problems around its perceived value became clear when many of the students' parents did not grant permission for their children to participate. Twenty-six of the 71 students did not go on the trip. The reasons were varied. A Pakistani student told me that she needed to accompany her father to the hospital to act as an interpreter; an East Indian student, who had only recently joined the class, did not attend because her parents did not feel comfortable letting her go. Many of the Chinese students did not participate because they had family responsibilities. Kevin was not able to attend because he was responsible for picking up his younger brother from day care and his sister from school while his parents worked. Bing could not participate because he worked in his family's tea store and was sometimes called upon to complete customs forms and other documents.

I had assumed that the students would want to participate in the field trip, and that those students left behind would feel resentful. The students with whom I spoke, however, did not seem especially resistant to their parents' refusal to allow them to participate. When I shared an earlier draft of this paper with her, a colleague commented that perhaps the sense of selfesteem gained from contributing in important ways to the well-being of the family contributed to their sense of identity in a more significant way than the freedom to take part in a school trip. 
Of the Chinese students who participated, Mandy, Elsa, and Annie said that, although they were not usually permitted to attend sleepovers at their friends' homes, they were permitted to go on school-sponsored field trips: "if it's for school, it's okay!" (Field note: November 2000). They spoke of how their parents had a high regard for school and for their teachers, and schoolsponsored activities were viewed in a different light from those initiated outside of school. Nevertheless, although the activities were part of the curriculum and were supported by their teachers, their parents did not show the same commitment to the school's athletic, artistic, or outdoor-education activities as they showed for academic subjects such as science, mathematics, or English.

\section{Teacher perspectives interacting with parent perspectives}

It's against my religion for girls to go out. (Field note: November 2000)

Sahra was resigned to the fact that she would not be permitted to take part in the field trip. In fact she did not feel that she could even raise the issue with her father since she felt quite certain that such a request would not only be likely to be refused but would also anger her parents. William offered to speak with her father but, after some consideration, Sahra declined his offer. She explained that her parents had permitted her to participate in an outdoor-education overnight field trip 2 years earlier, but that it had been an exception. Her father had stated explicitly that her participation then had been a one-time exception and that she was not to ask again.

My discussion with William suggested that acknowledging the cultural diversity of his students around the trip by supporting the beliefs and values of their parents conflicted with his personal and professional knowledge. He felt strongly that his students should have the opportunity to take part in school-sponsored events, regardless of gender. It was difficult to support the wishes of some of his students' parents that girls not participate in some school activities and events. And, in the days prior to the departure for Boyne River, it became evident that many of the South Asian girls were not permitted to go. William pointed out that the younger brother of one of his students had been permitted to attend but that because his student was female, she was not allowed to.

A colleague with whom I discussed this incident responded in a way that was similar to William's reaction. She did not know how a public school could accommodate such differences in perspective around the rights and privileges of the female South Asian students - she is the parent of two daughters. Her husband also felt very strongly that the girls were having their rights infringed upon: as citizens in a democratic society, it is among our responsibilities to protect the rights of the girls and ensure that children are not denied learning opportunities because of their gender.

Thus, the interaction between William and Sahra highlighted the potential for tensions to develop when differences in perspective about the value of specific curriculum events arise. When William offered to speak to Sahra's parents, he hoped he could convince them to permit her to participate in the field trip. He was not aware of the history of Sahra having negotiated 
permission from her parents to take part in an earlier school field trip, nor was he aware of her agreement not to ask for permission to participate in subsequent overnight field trips.

Nor did William ${ }^{4}$ realize the extent to which the parents of some of the South Asian students at Bay Street School are relatively strict with respect to their children's participation in schoolsponsored activities away from the school's premises. In the 3 years since this incident, both William and I have learned about some of the practices of the students' families. We are now not surprised when a South Asian student tells us that he or she is not permitted to take part in swimming in physical education classes or go on a field trip. We know how many of the South Asian students fast for a month during the fall, how some of the students and their families regard structured prayer times as a very important aspect of their daily lives, and how some students engage in elaborate washing rituals prior to the prayers held in the library at the school on Friday afternoons. We know - from what some of the female South Asian students in William's class have said - that, with respect to some of the South Asian parents, male children are more likely than female children to be permitted to participate in the full range of school activities.

The teachers at Bay Street School realize that their beliefs about curriculum sometimes differed from those of the parents of their students - to the point of conflicting - and that they were faced with the dilemma of how to "accommodate" for such vastly different views. Thus, William was aware that the cultural and social narratives guiding his practices might differ from those guiding the parents of his students, and he was committed to acknowledging the diversity of his students. However, he had not anticipated that his professional identity would come in conflict with values held by some of his students' parents. The Boyne River field trip highlighted the extent to which the implementation of curricular practices seemed to conflict, at times, with his, and his colleagues', beliefs about the "needs" of their students of ethnic minority background. However, it was not until he was faced with a situation where the differences hindered the implementation of an activity he supported that the differences became problematic. When differences in perspective did not have an effect on practice, supporting these differences did not challenge his beliefs, or involve high stakes.

Regardless of the reasons for the parents not wishing their children to participate, we must ask how appropriate it is for a teacher to attempt to influence these decisions. Thus, William had the best of intentions when he offered to speak to Sahra's parents about the Boyne River field trip; he recognized the value of the field trip and wanted to instill in Sahra and his other students an appreciation for the importance of equality of opportunity regardless of gender. He had not realized the potential that his intervention might have to create conflict between Sahra and her parents.

William's offer could also be viewed in terms of his rights and his role as Sahra's teacher in relation to the rights and roles of Sahra's parents as they worked to instill in Sahra the beliefs that they valued. In a situation where her parents and her teachers agreed about the values they would like to instill, Sahra would have had the support of both her parents and her teacher. However, William wanted Sahra to have the opportunity to experience an outdooreducation center while her parents did not think such a field trip would be appropriate for a 
young woman. Sahra was caught in the middle: she was a child growing up in an immigrant family whose values differed significantly from those supported in her Canadian school context.

William did not approach Sahra's parents. However, what should teachers do in situations of this kind? What is the formal framework pertaining to student participation in school activities, in general and at Bay Street School in particular? What are the ethics of introducing beliefs and ideas, and engaging students to support these perspectives, when their parents would be opposed to them? Is suggesting to parents that they permit their children to participate in activities they do not value an instance of crossing ethical and professional boundaries? In attempting to convince parents to reconsider their decisions about school activities, are teachers conveying to students, and their parents, that they are more appropriate guides for the development of values and choice of practices than their parents? By stating, openly or tacitly, that they do not support the specific values guiding parents' decisions, are teachers putting students in the middle? A culturally sensitive curriculum is sine qua non of contemporary schooling; the issues around the Boyne Rover field trip highlight the complexity of these issues.

Differences in opinion around the appropriate behavior of and toward female students also surfaced on another occasion. After hearing from some of the female students in his class that a grade-7 boy from an adjourning classroom had been behaving inappropriately with them, William scolded them for not telling him about it sooner. He then emphasized to them that they had a right to expect to be treated with respect. As I watched the interaction, I was reminded that some of his students lived such different realities between home and school with respect to ideas about the role of women in society. The students were standing at the door of the classroom, wearing head coverings, preparing to return home to families where they lived with codes of behavior that define the position of women in the home and society as very different than that of males. Their teacher was telling them that "no one has the right to make you feel less of a person!" (Field note: March 2002). I wondered whether their parents would have encouraged them to take such a stance, or to do so in the way William was suggesting.

The intersection of cultures also became apparent as students and their parents negotiated ways in which their home culture would be adhered to in their school context. As I have indicated, many of the female, South Asian students at Bay Street School wear a head covering, a hijab, when they are outside of the home. I found it interesting that many of the girls who usually wear hijab to school did not wear them for their graduation ceremony, photos, or the party afterward.

I noticed one day that Miriam, who did not usually wear the hijab, had begun wearing one. She explained that her South Asian friends in her homeroom class had pressured her into wearing it because it was Ramadan, the holy month during which many members of the South Asian community at Bay Street School fast during daylight hours. I looked around and indeed all of the South Asian girls in William's class that year were wearing hijab. Miriam said that her mother was not strict about her wearing the hijab and had left it to her to decide whether or not to wear it. She had decided against it; but when her friends started to pressure her, she wore it. She continued to wear the hijab to school, and from that day until one day toward the end of her grade- 8 year, I did not see her hair again because it was always covered. She did not, however, wear the hijab for her graduation photos or for her class photos. 
Sahra and Miriam told me that wearing the hijab is a serious responsibility. The girls and their families decide whether or not to wear the hijab when the girls are young; once they reach puberty, it is a responsibility that is expected of them. Moreover, once they begin to wear the hijab, they are not to stop. Mrs. Mohamed, a teacher at Bay Street School, told me that her older daughter had chosen on her own to wear the hijab when she was very young. "I didn't want her to. I told her, 'Once you start wearing it, you cannot stop.' But she wanted to wear it, and since she was 8 , she has always worn the hijab. She was the first of all her friends to wear it." I thought I detected a hint of pride in her voice, which I did not quite understand.

I have been told by members of the Bay Street School community (and read) that some South Asian women find wearing the hijab to be liberating: It provides protection from unwanted attention when out in the streets, and is worn with pride. I had not realized until I began writing about this incident that (I think) I had seen the hijab as a reminder that some opportunities were available to South Asian men but not to South Asian women. I had not understood how it could be liberating to be told to wear something because someone else deemed it appropriate. I might even have believed that those who were wearing the hijab would be more likely to adhere to traditional practices that define the role of women in more restrictive ways than that of men.

In my discussions with William, he also indicated that he sees wearing the hijab as a form of oppression of women. He reasoned that since women are wearing them because they are being told, or required to, rather than out of freedom of choice, it cannot be a form of liberation. He further argued that if men are not required to wear hijab while women are, then it cannot be viewed as a form of liberation for women. William also indicated how he views South Asian women as having less freedom within their culture than do men: he does not see the need for a man to accompany his wife, or mother, or sister when they are doing errands outside the home, as he sees some of the South Asian men in the community do. As a response to these observations, William's teaching colleague, Lina, suggested that "Maybe it's for their protection"; to which William responded, "If it's the men that are harassing the women, then they are the problem, not the women. Don't you think that it would be a burden, to have someone accompanying you all the time?"

As with the Boyne River field-trip situation, the tensions with respect to the practice of wearing the hijab highlight dilemmas. Thus, William believed that individuals have the right to choose what they will wear and that the practice of wearing the hijab discriminated against women. At the same time, he wanted to support the parents' attempts to instill their ethnic and religious values in their children. Here we have an interaction of beliefs and values within an individual teacher: He would like to instill in his students values he supports; he also realizes that he may not agree with some of the practices supported by the parents of his students. In a larger sense, there is a tension in that the rights of the individual conflict with the rights of a school to put in place practices and support behaviors that reflect the values respected in the school context but which may conflict with the right of parents to raise their children in ways they deem appropriate. 


\section{Confronting personal biases to meet on landscapes of difference}

The importance of teachers making curriculum decisions and interacting with students and their parents in ways free from bias is a quality that is appreciated in a culturally diverse society. What is not often acknowledged, however, is that as humans whose beliefs and values have been shaped by prior experiences and interactions, teachers come to teaching with strong views about some aspects of teaching. These strong views may also be interpreted as "biases" in some situations.

For example, I had thought of myself as relatively accepting of difference and tolerant of cultural diversity. However, as I reflected upon how I had written about the role of women in the South Asian community at Bay Street School and about what William and I thought wearing the hijab meant, I realized-with a fair amount of discomfort-that I had judged these practices using my own perceptions of their meaning. I was presenting the practice of wearing a hijab and of "serving men" as examples of ways in which women are valued less than men in South Asian culture, and interpreting in a stereotypical way the role of women in the South Asian community as submissive to that of the men.

I also realized that I was making assumptions about practices without understanding the reasons individuals accepted them, and then judging them by my own beliefs. I overlooked things that I did know that suggested that I needed to reconsider my interpretations. An example: one South Asian woman who works at Bay Street School built a new life in Canada for her three school-aged children and herself after her husband died suddenly shortly after their arrival in Toronto. I also overlooked that Mrs. Mohamed, whom I had been judging as very "traditional" in her attitudes-I had heard from William's teaching colleague that she had placed an ad in the local South Asian newspaper in search for an appropriate husband for her 19-year-old daughter - was an architect before immigrating to Canada, and that she supported her daughter's plans to study medicine. She had also raised four children on her own when she had arrived in Canada a few years before her husband was able to emigrate. Thinking about this reminded me that there is much that I do not know about South Asian communities, and that I need to be cautious about judging their practices.

Thus, as I have reflected on the interaction of personal and professional beliefs and values as teachers, students, and parents at Bay Street School live the curriculum, I have to realize the potential of these values and beliefs to shape the work of teachers-as well as their potential role in shaping the work of researchers who undertake research with teachers. I was making generalizations based on an assumption that the behaviors and practices of members of the South Asian community would be uniform. Thus, while I have been contending that Chinese culture cannot be defined by specific traits, characteristics, or practices, I was making assumptions about members of the South Asian community based on generalizations. I was also troubled that my perception of myself as accepting and tolerant was being challenged, and I wondered-and worried about-what this might mean for someone who works with diverse school communities.

Were my feelings similar to those experienced by Dave in the weeks that followed a disagreement during a School Council meeting? ${ }^{5}$ Dave felt that he was being perceived as racist 
when he publicly disagreed with the views of a Black parent about how a Black child who had not complied with school regulations had been disciplined. From conversations with Dave, and from observations of him interacting with students and teaching lessons in which he demonstrated a willingness to address issues of diversity, racism, injustice, I perceived Dave to be supportive of the causes of members of ethnic minority groups. When he expressed an opinion different from that of a Black parent in the School Council meeting, however, he was perceived as racist. Dave expressed frustration at this label and was indignant that he could not have views that differed from those of someone of an ethnic background different from his own without worrying about offending them. He worried that, as a male of European background, if he took a firm viewpoint, he would be perceived of as representing a privileged position. My reflection upon the incident, and my conversations with members of the school community, lead me to wonder whether his positive attitude toward diversity and willingness to learn about the languages and cultures of his students were sufficient. Sensitivity and tolerance for difference are admirable traits, but they need not be at the expense of the freedom to express differences in opinion without fear that these differences would be interpreted as racist or discriminatory.

This Council meeting led to months of discussion among some teachers at Bay Street School about diversity, racism, school policies pertaining to diversity, and their role as teachers in modeling appropriate behaviors and attitudes. These conversations in turn led me to reflect upon the tensions among the members of the School Council. I have heard individual members of the Council speak with conviction about their commitment to working together to create as positive a learning environment as possible for the sake of the children in the school. In my experience of interacting with members of the School Council, I have found them to be sensitive and supportive of the diversity in the Bay Street School community. However, I wondered what the disagreement meant to the individuals who had been directly involved.

Thus, the difficulties in accommodating for the diverse perspectives and beliefs of those involved in the lived experience of curriculum highlight the need to explore in greater detail what it means to develop, and implement, a "culturally sensitive curriculum." With respect to the implementation of the Boyne River field trip, the teachers were demonstrating sensitivity to differences in values and beliefs as they sought to accommodate the parents who did not want their children to participate in the activity. ${ }^{6}$ However, while it may be perceived as "culturally sensitive" to accommodate for the parents' wishes, it may also be perceived as culturally sensitive to raise the awareness of the students involved by highlighting and addressing the differences in perspective. This approach might be likened to Ali's (2004) argument for the importance of acknowledging potentially sensitive issues by raising them such that they may be explored and discussed.

In other words, reflection upon the responses of the teachers, including myself, highlights the complexity of the issues involved in sensitivity to ethnic, religious, and linguistic diversity in a school context, and reinforces the extent to which we are, as the receiving culture, unprepared to deal with some of the issues that arise. 


\section{Conclusion}

Interaction among students of diverse ethnic backgrounds in a supportive school environment provides a context where positive attitudes toward race and ethnicity may develop (Banks 1995). This approach reinforces the importance of schools in creating opportunities for exposure to, and interaction with, individuals of diverse backgrounds. However William and Dave's experiences of working with their ethnically, linguistically, and religiously diverse students reveals the extent to which mere exposure, and even good intentions and specific ideas about ways in which culture may be acknowledged through school practices, are insufficient and leave some important questions unresolved.

Thus, William's experience around the Boyne River field trip shows how acknowledging cultural diversity can be a challenge. What does it mean for a school community to be "accepting" of diversity? How does a knowledge and an acceptance of differences affect the teaching of values that are normative in the larger community while, at the same time, supporting practices that are important to parents, but may not accord with the larger community's values? While it may be possible to achieve tolerance, how do teachers acknowledge and incorporate conflicting values? Would William, in accommodating for the values of his South Asian students, be indirectly expressing a lack of support for a majority group whose values differ significantly from those of the minority? If he accommodated for a group whose values he does not support, is he nonetheless supporting those values by conceding?

Teachers bring to their teaching beliefs and values shaped by their own experiences of teaching, and being taught. Cohen (1989, see Ball 1990: 274) sees teaching practices and beliefs as "deep-seated dispositions, simmered over the years of a teacher's experience and seasoned by cultural assumptions about and images of teaching and learning." Given the role of experience in shaping perceptions of curriculum, we can expect that teachers' practices and beliefs about incorporating culture in the curriculum would be shaped by their own experiences of culture in their school curriculum. Difficulties arise, however, when we realize that many teachers do not have such curricular experiences to draw on.

Cohen and Ball (1990: 352) raise the question, "How can teachers teach a mathematics that they never learned, in ways that they never experienced?" in their examination of teachers' experiences of mathematics curriculum reform. A similar question emerges around the implementation of a culturally sensitive curriculum. The changing demographic composition of communities in North America, Europe, and Australia implies that teaching is vastly different than it was 40, or even 20, years ago-when today's teachers experienced schools themselves as students. Teachers working in settings such as Bay Street School are faced with the challenges of acknowledging in a positive way diverse cultures, but many are doing so without a professional knowledge base, or the personal experience of having themselves lived school contexts of this kind.

In addition, while teachers' beliefs and practices are "simmered over the years of a teacher's experience and seasoned by cultural assumptions about and images of teaching and learning" (Cohen 1989, see Ball 1990: 274), the parents of the students they teach also bring their own "deep-seated dispositions" to the curriculum landscape, simmered over years of schooling in 
their own cultures, shaped by the interaction of the cultural and social narratives unique to their own situations. These experiences in turn shape their values and beliefs about curricula they interpret as appropriate. In some instances, as with the Boyne River field trip, the beliefs that some families bring to the school context differ in significant ways from the values guiding the practices of others - to the extent that they are in conflict.

These are no easy answers to these questions. However, it is clear that even the teachers who work at Bay Street School-with its tradition of accepting diversity - and who demonstrate a willingness to learn about diverse cultures and languages, and believe in equality and equity for their students regardless of cultural backgrounds and gender need to address and discuss the events that may arise as diverse cultures intersect on their school landscapes, to identify issues of relevance to the particular ethnic communities involved.

The teacher, student, and parent responses to the Boyne River field trip highlight the extent to which the receiving cultures of immigrants need to explore ways of accommodating for this diversity in school contexts. We have the expectation that children of ethnic minority background need to "adapt" to "our" school communities, but we may overlook that, as a host country for immigrants, we also need to explore the extent to which this relationship may be reciprocal. We need to explore ways of accommodating for diverse cultures in ways that are respectful of the differences. At the same time, we need to provide as rich an experience of "our" schooling as possible for the children involved. By addressing potentially sensitive issues, we begin the process of uncovering the "secret stories" (Clandinin and Connelly 1996: 25 ) that may hinder our ability to meet the needs in our school communities. For example, is a belief in the rights of girls that may lead us to disrespect the views of conservative South Asian parents who are living in another world an example of a secret story that needs to be raised for discussion. Sensitivity to such stories also allows us to explore our role in facilitating the acculturation of individuals of ethnic-minority background through the curricula we implement.

Acknowledgments - I would like to express my heartfelt thanks to F. Michael Connelly of the Ontario Institute for Studies in Education, the University of Toronto, and to D. Jean Clandinin of the University of Alberta for their contribution to my research and graduate student experience. This study was generously supported by a Social Sciences and Humanities Research Council (SSHRC) of Canada Doctoral Fellowship.

\section{Notes}

1. This research was part of a larger study examining the ethnic identity of first generation Canadians in a multicultural school context (Social Sciences and Humanities Research Council (SSHRC) Doctoral Fellowship 752-2001-1769), which was in turn embedded in F. M. Connelly and D. J. Clandinin's longterm SSHRC-supported program of research examining the diverse cultural landscapes of experience that students, parents, and educators bring to the professional knowledge landscape of an elementary school (Standard Research Grants - "Landscapes in Motion; Landscapes in Transition"; "Landscapes in Transition; Negotiating Diverse Narratives of Experience"; and "Intersecting Narratives: Cultural Harmonies and Tensions in Inner-City Canadian Schools"). As I worked at Bay Street School, my observations and interactions with the teachers were guided by the following kinds of questions: What kinds of curriculum events and activities did the teachers plan? How do the teachers understand 
the home cultures of the students? How do they accommodate for the diversity of their students in their everyday interactions?

2. To learn about William's and Dave's experiences of culture in the curriculum on this multicultural school landscape, I interacted with them over the course of hundreds of hours of school visits. I began observations at the school during the spring of 2000 and continued until the spring of 2003 for the larger project of which this study is part. Field notes for this study were written during the 2000-2001 school year I spent with William and his teaching colleague, Dave, and their combined classes of 71 grade-8 students at Bay Street School. I wrote field notes following school visits, staff meetings, field trips, classroom observations, school assemblies, and interaction with members of the school community at events such as Multicultural Night, Curriculum Night, and School Council meetings. These field notes, along with interview transcripts, researcher journals, and theoretical memos, were filed in an existing project archival system. I also collected documents such as school notices, announcements of community and school events, notices posted on bulletin boards and classroom walls, agendas and minutes from School Council meetings, newspaper clippings of local media coverage, and samples of student work to learn about ways in which the interaction of diverse cultures played out in the school context.

3. The neighborhood community from which the student population is drawn reflects immigration patterns of recent immigrants into Toronto. Families who have recently immigrated to Canada settle in the community (Makhoul 2000) before moving to suburban communities as they become more established.

4. He was just a few months into his first year of teaching at the time.

5. School Councils were established by the provincial ministry and local school boards, in part, to facilitate the process of parents and teachers working together (Ministry of Education and Training 2004a, b).

6. Although teachers may not have much choice in this matter, since teachers at Bay Street School seem to accept parent decisions about whether their children are permitted to participate in specific curriculum activities or not, the students whose parents did not grant them permission were deprived of the enjoyment and educational value of the activity.

\section{Author Information}

Elaine Chan is a Social Sciences and Humanities Research Council of Canada postdoctoral fellow in the Department of Curriculum, Teaching and Learning at the Ontario Institute for Studies in Education, University of Toronto, 252 Bloor Street West, Toronto ON, M5S 1V6, Canada; email elchan@oise.utoronto.ca. She has research interests in the ethnic identities of first- and second-generation Canadians, the interaction of culture and curriculum in school contexts, and student and teacher experiences of educational equity policies on multicultural school landscapes.

\section{References}

Ada, A. F. (1988) The Pajaro Valley experience: working with Spanish-speaking parents to develop children's reading and writing skills through the use of children's literature. In T. Skutnabb-Kangas and J. Cummins (eds), Minority Education: From Shame to Struggle (Clevedon, UK: Multilingual Matters), 223-238.

Ali, N. (2004) Meaning-making for South Asian immigrant women in Canada. Doctoral dissertation, University of Toronto. 
Ball, D. (1990). Reflections and deflections of policy: the case of Carol Turner. Educational Evaluation and Policy Analysis, 12(3), 263-275.

Banks, J. A. (1995) Multicultural education: its effects on students' racial and gender role attitudes. In J. A. Banks and C. A. McGee Banks (eds), Handbook of Research on Multicultural Education (Toronto, ON: Prentice-Hall), 617-627.

Chan, E., and Ross, V. (2002) Report on the ESL survey: sponsored by the ESL Workgroup in collaboration with the OISE/UT Narrative and Diversity Research Team (Toronto: Centre for Teacher Development, Ontario Institute for Studies in Education of the University of Toronto).

Clandinin, D. J., and Connelly, F. M. (1994) Personal experience methods. In N. K. Denzin and Y. S. Lincoln (eds), Handbook of Qualitative Research in the Social Sciences (Thousand Oaks, CA: Sage), 413-427.

Clandinin, D. J., and Connelly, F. M. (1996) Teachers' professional knowledge landscapes: teacher stories-stories of teachers-school stories-stories of schools. Educational Researcher, 25(3), 24-30.

Clandinin, D. J. and Connelly, F. M. (2000) Narrative Inquiry: Experience and Story in Qualitative Research (San Francisco, CA: Jossey-Bass).

Cohen, D. K. (1989) Teaching practice: Plus ça change. In P. W. Jackson (ed.), Contributing to Educational Change: Perspectives on Research and Practice (Berkeley, CA: McCutchan), 27-84.

Cohen, D. K., and Ball, D. L. (1990) Policy and practice: an overview. Educational Evaluation and Policy Analysis, 12(3), 347-353.

Connelly, F. M., and Clandinin, D. J. (1988) Teachers as Curriculum Planners: Narratives of Experience (New York: Teachers College Press).

Connelly, F. M., and Clandinin, D. J. (1999) Stories to live by: teacher identities on a changing professional knowledge landscape. In F. M. Connelly and D. J. Clandinin (eds), Shaping a Professional Identity: Stories of Educational Practice (London, ON: The Althouse Press), 114-132.

Connelly, F. M., Phillion, J., and He, M. F. (2003) An exploration of narrative inquiry into multiculturalism in education: reflecting on two decades of research in an inner-city Canadian community school. Curriculum Inquiry, 33(4), 363-384.

Cummins, J. (1996) Negotiating Identities: Education for Empowerment in a Diverse Society (Ontario, CA: California Association for Bilingual Education).

Dewey, J. (1938) Experience and Education (New York: Simon \& Schuster).

Igoa, C. (1995) The Inner World of the Immigrant Child (New York: St. Martin's Press).

Kouritzin, S. G. (1999) Face(t)s of First Language Loss (Mahwah, NJ: Lawrence Erlbaum Associates).

Makhoul, A. (2000) Ryerson Community School-Where You Belong. Caledon Institute of Social Policy. Available online at: http://www.caledoninst.org, accessed 5 May 2005.

McCaleb, S. P. (1994) Building Communities of Learners: A Collaboration among Teachers, Students, Families and Community (New York: St. Martin's).

Ministry of Education and Training (2004a) About the OPC: History and Role of the OPC. Available online at: http://www.ontarioparentcouncil.org/about_the_opc/default.asp?load=contributions1, accessed 14 September 2004.

Ministry of Education and Training (2004b) School Councils. Available online at: http://www.ontarioparent council.org/school_councils/Default.asp?language=English, accessed 14 September 2004.

Moodley, K. A. (1995) Multicultural education in Canada: historical development and current status. In J. A. Banks and C. A. McGee Banks (eds), Handbook of Research on Multicultural Education (Toronto, ON: Prentice-Hall), 801-820.

Paley, V. G. (1995) Kwanzaa and Me: A Teacher's Story (Cambridge, MA: Harvard University Press). 
Phillion, J. (2002) Becoming a narrative inquirer in a multicultural landscape. Journal of Curriculum Studies, 34(5), 535-556.

Rodriguez, R. (1982) Hunger of Memory: The Education of Richard Rodriguez (Boston, MA: David R. Godine).

Schwab, J. J. (1973). The practical 3: translation into curriculum. School Review, 81(4), 501-522.

Statistics Canada (1998) 1996 Census: Ethnic origin, visible minorities. Available online at: http://www .statcan.ca/Daily/English/980217/d980217.htm, accessed 19 September 2005.

Statistics Canada (2003) Census of Population: Immigration, birthplace, and birthplace of parents, citizenship, ethnic origin, visible minorities, and Aboriginal peoples. Available online at: http://www.statcan.ca/Daily/ English/030121/d030121a.htm, accessed 19 September 2005.

Wong-Fillmore, L. (1991a) When learning a second language means losing the first. Early Childhood Research Quarterly, 6(3), 323-346.

Wong-Fillmore, L. (1991b) Language and cultural issues in the early education of language minority children. In S. L. Kagan (ed.), The Care and Education of America's Young Children: Obstacles and Opportunities. 90th Yearbook, Part 1, of the National Society for the Study of Education (Chicago: University of Chicago Press), 30-50. 